\title{
Intermittent axillary vein obstruction in a competitive canoeist
}

\author{
J. R. Livesey, FRCS(Ed) \\ The Queen Elizabeth Military Hospital, Woolwich, London SE 18
}

\begin{abstract}
The case is reported of a competitive canoeist with intermittent axillary vein obstruction secondary to shoulder girdle muscle hypertrophy. The anatomy of the axilla, pathology of the axillary vein, and reported cases of sports injuries involving the axillary vein are discussed. This would appear to be the first report of such an occurence in a canoeist.
\end{abstract}

Keywords: Axillary vein obstruction, canoeing, sports injury, venography

\section{Introduction}

In competitive canoeing a high level of motivation and intensity of mental effort is essential ${ }^{1}$. Many hours of training are required to build up and maintain the individual's strength and stamina. Muscular disproportion occurs with marked hypertrophy of the shoulder girdle muscles with the potential to affect the contents of the axilla.

\section{Case report}

A 22 year old right handed Caucasian male teleprinter operator presented with a 12 month history of intermittent swelling, blue discolouration and incoordination of his right hand and forearm. These symptoms were precipitated by right arm dependency for more than 20 minutes and made tasks such as writing and typing difficult, due to 'tightness' in his hand. Abduction of his right arm produced rapid symptomatic relief.

A non-smoker, the patient took no medication, had no allergies and had neither a past medical nor family history of note. The patient was a competitive canoeist and spent up to six hours training every day.

On examination, the patient had well developed shoulder girdle muscles with normal skin, pulses, power and sensation in both upper limbs. There was no evidence of a cervical rib, neck bruit, supraclavicular nor axillary mass.

Dependency of both arms for 20 minutes produced blue discolouration, mild swelling and inco-

Address for correspondence: Mr J. R. Livesey, Royal Surrey

County Hospital, Park Barn, Guildford, Surrey, UK.

(C) 1990 Butterworth-Heinemann Ltd

0306-4179/90/020127-03 ordination of his right hand, whilst his left hand remained normal. The dorsal veins of both hands were noted to be full and equally prominent. These signs resolved with abduction of the arms to $90^{\circ}$. Strong radial and ulnar pulses were palpable throughout and normal capillary filling was noted. Clinical examination was otherwise unremarkable.

A full blood count, erythrocyte sedimentation rate and clotting profile were normal. Chest, thoracic inlet and shoulder radiography were all normal.

In order to differentiate between lymphatic and venous pathology, nuclear medical lymphoscintigraphy and contrast venography of the right arm were performed. For both procedures the patient lay supine on the examination table. The lymphoscintigram demonstrated normal, free flowing lymphatic channels.

With the arm by the patient's side, the venogram demonstrated compression of the axillary vein along its entire length with venous stasis (Figure 1). On abducting the arm by $24^{\circ}$ the axillary vein opened completely, allowing free drainage of the venous system (Figure 2).

The radiologist commented that this represented external compression of the axillary vein in the adducted position which, with the patient's disproportionate upper body musculature, was probably due to muscular hypertrophy. The lumen of the axillary vein was normal.

The patient was advised to refrain from canoeing for four months. On review after four months, the patient's signs and symptoms had resolved though there was no apparent change in the size of his shoulders. The venogram was repeated and again demonstrated total compression of the right axillary vein which cleared on abduction. Radiologically, no significant change was thought to have occured.

The patient was advised to refrain from canoeing for a further four months. When reviewed four months later, the patient had remained asymptomatic, again with no apparent change in his shoulder size. The patient was advised that he could resume canoeing though should his symptoms recur, he should consider changing his sport.

\section{Discussion}

The axillary vein is formed by the confluence of the brachial vein and venae comitantes of the brachial 
artery above the inferior border of the posterior wall of the axilla. The axillary vein ascends on the medial aspect of the axillary artery leaving the axilla anterior to the third part of the subclavian artery ${ }^{2}$.

The axillary vein lies sandwiched between the anterior and posterior walls of the axilla. Pectoralis

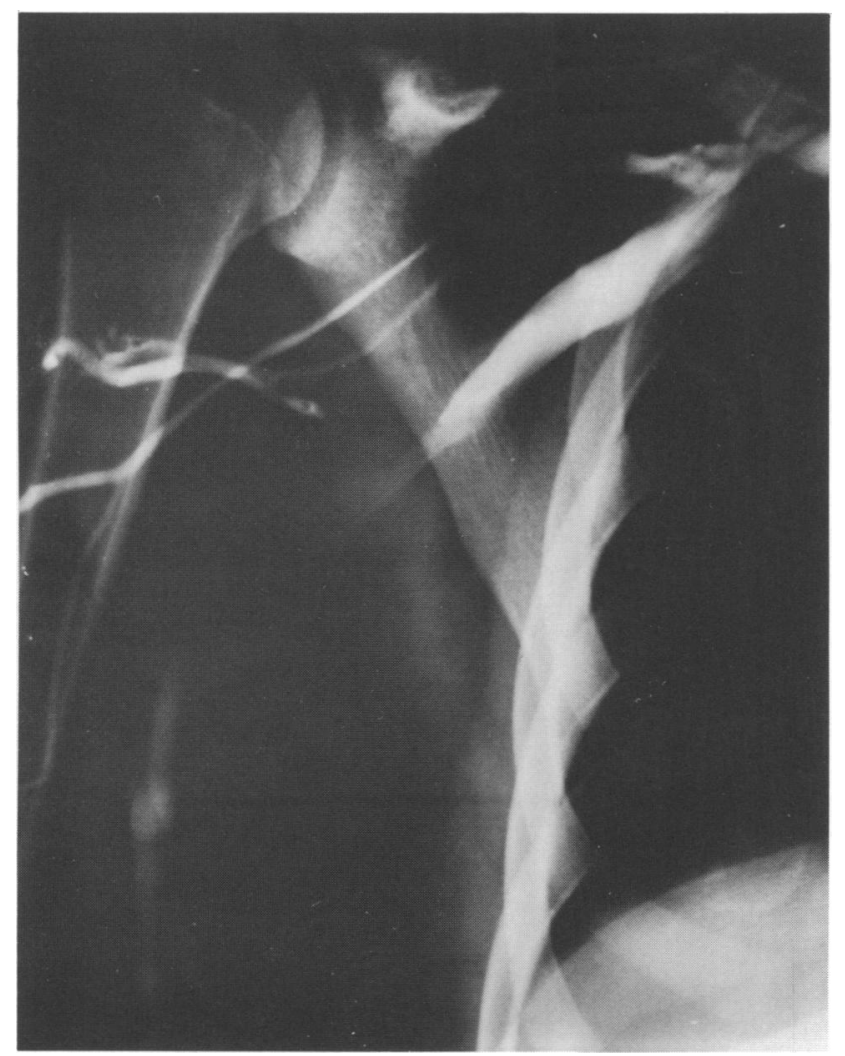

Figure 1. Right arm venogram demonstrating compression of the axillary vein along its entire length with the arm by the patient's side

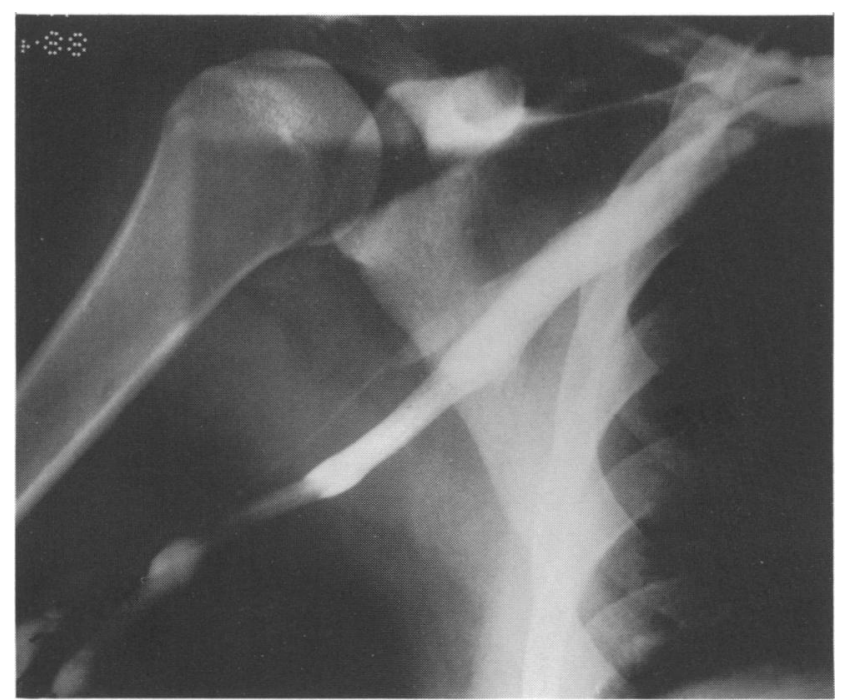

Figure 2. Right arm venogram demonstrating free-flow through the axillary vein with $24^{\circ}$ of abduction major is the principal muscle of the anterior wall whilst latissimus dorsi sweeps around the inferior border of teres major as it lies inferior to subscapularis, in the posterior wall. These four muscles insert respectively into the lateral lip, floor and medial lip of the bicipital groove and the lesser tuberosity of the humerus i.e. on the anterior aspect of the humerus (Figure 3). The axilla is thus triangular in transverse section (Figure 4) ${ }^{2}$.

Electromyography has shown that during canoeing exercise a major protagonist muscle during the pulling phase of the stroke is the latissimus dorsi ${ }^{1}$. Hypertrophy of this muscle and pectoralis major may compress the axillary vein. Unfortunately, no clinical method was available for quantifying changes in the size of this patient's shoulder muscles.

It is well recognized that after unaccustomed use of the arm the axillary vein may thrombose. The vein intima is thought to be damaged by excessive movement between the clavicle and first rib. Thrombosis produces painful congestion and oedema of the arm which subside as the collateral venous circulation develops. The serious sequelae of venous thrombosis (e.g. pulmonary embolism) are uncommon following an axillary vein thrombosis ${ }^{3}$.

Despite a 12 month history, this patient had no signs of an axillary vein thrombosis or its sequelae. Compression by the smooth and broad hypertrophied muscles of the axillary wall may cause less intimal damage than compression between the narrow and hard clavicle and first rib.

There have been few reported cases of axillary vein pathology associated with sport. O'Leary et al. reported four cases with post-exertional shoulder and or arm discomfort due to acute or possible impending axillary-subclavian vein thrombosis ${ }^{4}$. One patient required local streptokinase infusion, resection of the first rib and transvenous angioplasty to regain the full patency of a stenosed and obstructed axillarysubclavian vein. Another patient had a patent though narrowed and tented vein which was treated with heat and elevation prior to surgical correction ${ }^{4}$.

Follis reported a case of effort thrombosis of the axillary vein caused by violent abduction of the arm raising a $40 \mathrm{~kg}$ weight above the head ${ }^{5}$. Conservative treatment with anticoagulation, antibiotics and rest resulted in a slight functional deficiency at one year though venography showed good re-canalisation of the clot. Follis commented that the close relationship between the axillary vessels and surrounding anatomical structures may, during violent effort and in a particular position, cause compression of the vein with damage to the intima and clot formation ${ }^{5}$.

In summary, venography demonstrated intermittent obstruction along the entire length of the axillary vein due to external compression, due to hypertrophy of the musular boundaries of the axilla. It is surprising that intermittent axillary vein obstruction has not been previously reported in canoeists.

\section{Acknowledgements}

I would like to thank Col KM Stephens and Col J Ryan for their advice. 


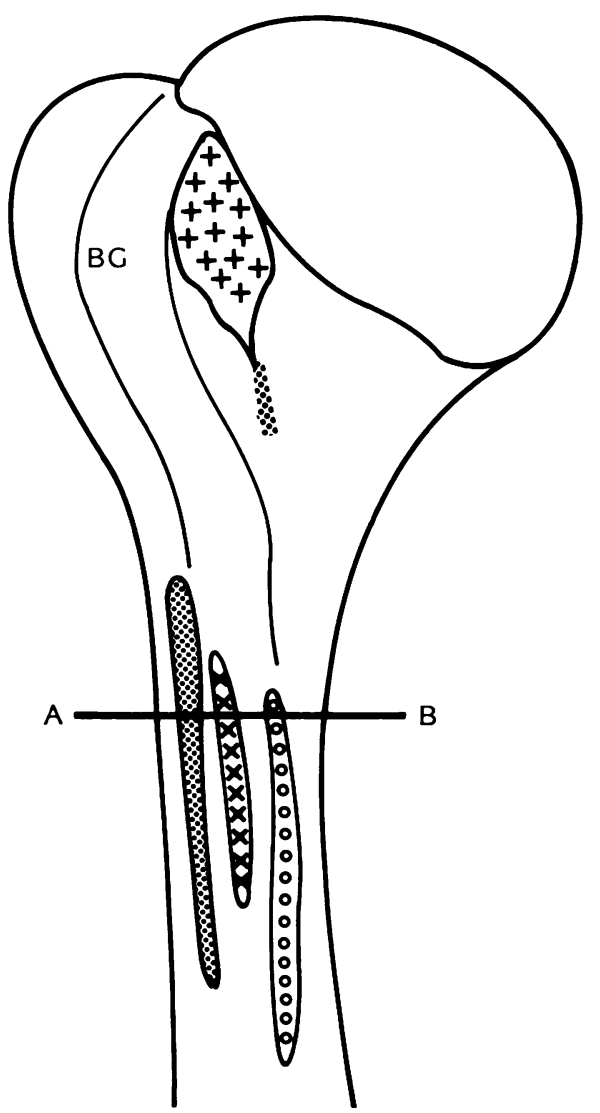

Figure 3. Sketch showing the anterior aspect of the right humerus with muscle insertions

\section{References}

1 Baker, S.J. and Hardy, L. Effects of high intensity canoeing training on fibre area and fibre diameter in the latissimus dorsi muscle $\mathrm{Br} J$ Sports Med 1989, 23, 23-26

2 Last, R.J. 'Anatomy, Regional and Applied.' 7th ed. Churchill Livingstone, UK, 1984, 53-63

3 Harding Raines, A.J. and Mann, C.V. 'Bailey and

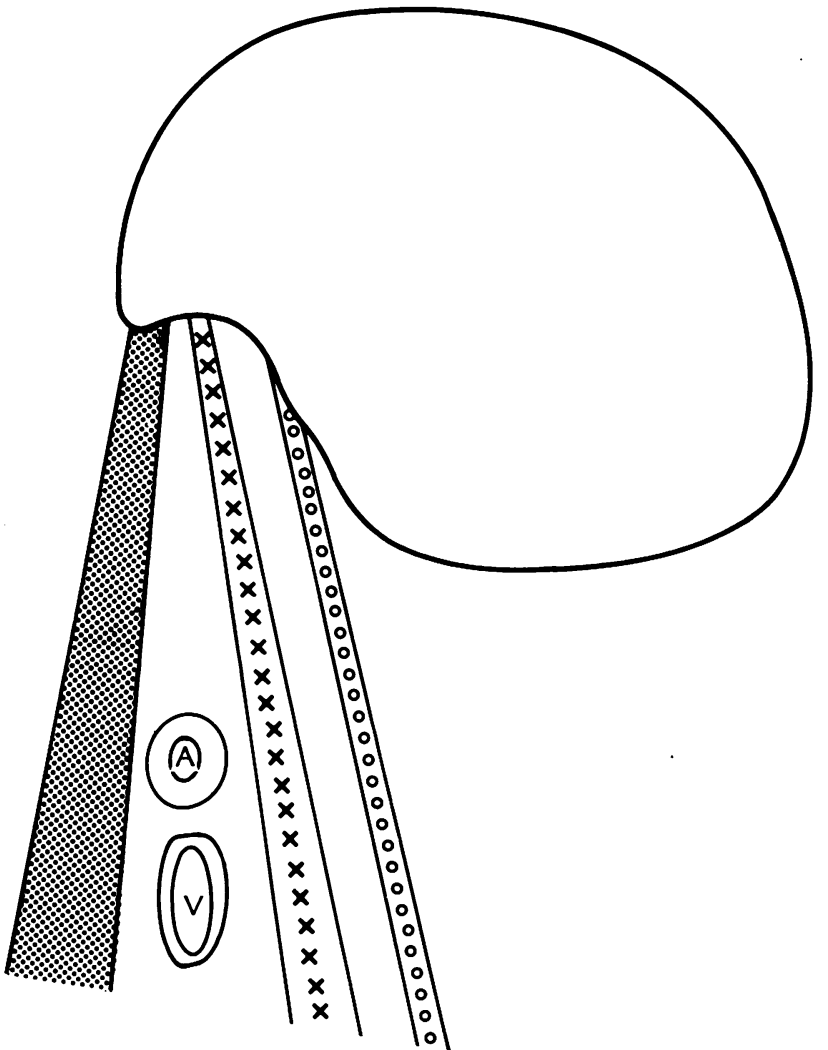

Figure 4. Sketch showing a transverse section through the shaft of the humerus at A-B

Key Subcapularis + , pectoralis major $\circledast$, latissimus dorsi $X$, teres major $O$, axillary artery $A$, axillary vein $V$, bicipital groove BG

Love's Short Practise of Surgery 20th ed. Lewis, UK, 1988, 170-8

4 O'Leary, M.R., Smith, M.S. and Druy, E.M. Diagnostic and therapeutic approach toa xillary-subclavian vein thrombosis Ann Emerg Med 1987, 16, 889-893

5 Follis, F. Primary thrombosis of the axillary and subclavian veins Minerva Chir 1977, 32, 1433-1438 